\title{
Prevalence and determinants of psychological insulin resistance among type 2 diabetic patients in Kinshasa, Democratic Republic of Congo
}

\begin{tabular}{|c|c|}
\hline \multicolumn{2}{|c|}{$\begin{array}{l}\text { Authors: } \\
\text { Shomba L. Rita' } \\
\text { Fina J.-P. Lubaki }{ }^{1,2} \\
\text { Lepira F. Bompeka } \\
\text { Gboyega A. Ogunbanjo } \\
\text { Lukanu P. Ngwala }\end{array}$} \\
\hline \multicolumn{2}{|c|}{$\begin{array}{l}\text { Affiliations: } \\
{ }^{1} \text { Centre Hospitalier } \\
\text { Mère-Enfant Monkole, } \\
\text { Kinshasa, The Democratic } \\
\text { Republic of the Congo }\end{array}$} \\
\hline \multicolumn{2}{|c|}{$\begin{array}{l}{ }^{2} \text { Department of Family } \\
\text { Medicine and Primary Health } \\
\text { Care, Protestant University of } \\
\text { Congo, Kinshasa, The } \\
\text { Democratic Republic of the } \\
\text { Congo }\end{array}$} \\
\hline \multicolumn{2}{|c|}{$\begin{array}{l}{ }^{3} \text { Service de Néphrologie, } \\
\text { Cliniques Universitaires de } \\
\text { Kinshasa, Kinshasa, The } \\
\text { Democratic Republic of the } \\
\text { Congo }\end{array}$} \\
\hline \multicolumn{2}{|c|}{$\begin{array}{l}{ }^{4} \text { Department of Family } \\
\text { Medicine, Sefako Makgato } \\
\text { University, Pretoria, } \\
\text { South Africa }\end{array}$} \\
\hline \multicolumn{2}{|c|}{$\begin{array}{l}\text { Corresponding author: } \\
\text { Shomba Lelo, } \\
\text { shombalelo@gmail.com }\end{array}$} \\
\hline \multicolumn{2}{|c|}{$\begin{array}{l}\text { Received: } 17 \text { Nov. } 2018 \\
\text { Accepted: } 19 \text { Feb. } 2019 \\
\text { Published: } 22 \text { July } 2019\end{array}$} \\
\hline \multicolumn{2}{|c|}{$\begin{array}{l}\text { How to cite this article: } \\
\text { Rita SL, Lubaki FJ-P, } \\
\text { Bompeka OA, Ogunbanjo GA, } \\
\text { Ngwala LP. Prevalence and } \\
\text { determinants of psychological } \\
\text { insulin resistance among type } \\
2 \text { diabetic patients in Kinshasa, } \\
\text { Democratic Republic of Congo. } \\
\text { Afr J Prm Health Care Fam } \\
\text { Med. 2019;11(1), a1993. } \\
\text { https://doi.org/10.4102/ } \\
\text { phcfm.v11i1.1993 }\end{array}$} \\
\hline \multicolumn{2}{|l|}{ Read online: } \\
\hline 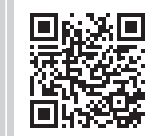 & $\begin{array}{l}\text { Scan this QR } \\
\text { code with your } \\
\text { smart phone or } \\
\text { mobile device } \\
\text { to read online. }\end{array}$ \\
\hline
\end{tabular}

Background: Psychological insulin resistance (PIR) is a common but unappreciated phenomenon by health care providers with a negative impact on the control of type 2 diabetes mellitus.

Aim: To determine the frequency of PIR and its determinants in patients with type 2 diabetes.

Setting: This study was conducted in Kinshasa in three health centres providing management of diabetic patients.

Methods: This study was a multicentric, cross-sectional study conducted from 01 November 2017 to 31 March 2018 in Kinshasa among 213 type 2 diabetic patients who were taking oral anti-diabetic drugs. A standardised questionnaire, the Chinese Attitudes to Starting Insulin Questionnaire (Ch-ASIQ), was used for data collection.

Results: The average age of participants was $59.8 \pm 11.1$ years with a male to female ratio of 1.5. The prevalence of PIR was 42.7\%; and its main determinants were 50 years of age (odds ratios [OR] adjusted 2.05; 95\% confidence interval [CI] 1.98-4.27; $p=0.045)$, the presence of complications (OR adjusted 3.33; 95\% CI 1.68-6.60; $p=0.001$ ), lack of knowledge about insulin therapy (OR adjusted 1.96; 95\% CI 1.03-3.71; $p=0.040$ ) and the high cost of insulin (OR adjusted 2.32; 95\% CI 1.08-4.95; $p=0.030)$.

Conclusion: The study showed that almost half of type 2 diabetic patients had PIR with the main determinant factors related to the patient and the health system. The establishment of a therapeutic education programme, improved 'provider-patient' communication and the development of approaches to increase access to drugs are crucial to reduce the prevalence of PIR.

Keywords: psychological insulin resistance, therapy; type 2 diabetes mellitus; frequency; determinants.

\section{Introduction}

The prevalence of type 2 diabetes mellitus is increasing exponentially worldwide. Particularly, low- and middle-income countries will carry a heavy burden in the next few years if there are no efforts made to prevent and ensure early detection and management of type 2 diabetes. ${ }^{1}$ In recent years, significant progress has been made, particularly in the development of new oral medications. However, the use of insulin remains essential at the evolutionary stage of the disease, because insulin resistance which is a characteristic of type 2 diabetes, leads over time to the depletion of beta cells of islets of Langerhans. ${ }^{2}$ In the United Kingdom Prospective Diabetes Study (UKPDS) study, ${ }^{3}$ less than $25 \%$ of normal insulin secretion was observed 6 years after diagnosis of the disease. Many patients with type 2 diabetes, who should benefit from insulin therapy during the course of their illness or in special circumstances, do not receive it at all or receive it outside of the required timing because of resistance. ${ }^{2}$ Psychological insulin resistance (PIR) can be explained by factors related to the patient, the provider and the health system..$^{2,4,5,6}$ Attitudes contributing to PIR include beliefs that receiving insulin is associated with an adverse outcome and/or outcome of the disease because of non-compliance by the patient, a restriction in lifestyle habits and stigma unfavourable to glycaemic control. ${ }^{2}$ Management guidelines, not recommending insulin therapy unless other strategies have failed to achieve glycaemic control, also contribute to this resistance to insulin therapy from health care providers. ${ }^{2}$ The factors leading to PIR vary in different settings. ${ }^{2}$ 
In the Democratic Republic of the Congo (DRC), the prevalence of diabetes mellitus is estimated at $4.8 \%{ }^{7}$ with type 2 diabetes causing high morbidity and mortality, as well as several acute conditions, such as infections, hyperosmolarity and surgical complications, requiring a switch to insulin therapy. ${ }^{8,9,10,11}$

The purpose of this study was to determine the prevalence of PIR in type 2 diabetic patients and its determinants in hospital settings in Kinshasa.

\section{Methods \\ Study design}

Our study was a cross-sectional study.

\section{Study period and setting}

The study was conducted in Kinshasa from November 2017 to March 2018, in three health facilities providing care to diabetic patients: specifically, the ${ }^{1}$ Centre Hospitalier Mère-Enfant (CHME) Monkole Diabetology Unit located in the MontNgafula 1 Health Zone, the Diabetic Clinic of the Tatamena Health Center located in the Bumbu Health Zone and the Diabetes Unit of the Strategos Medical Services (SMS) Center DRC located in the Gombe Health Zone. These health facilities organise outpatient consultations of diabetic patients at a weekly rate. At each medical consultation, patients receive training on diabetes and are examined for adjustments in their treatments according to the progression of the disease.

\section{Study population}

All diabetic patients followed at the CHME Monkole Diabetes Unit, the Tatamena Health Center and the DRC SMS Hospital Centre during the study period represented the study population.

\section{Selection criteria}

Patients were included in the study based on the following criteria:

- be a type 2 diabetic patient (any diabetic patient who had knowledge of the type of diabetes or had started diabetes after age 40)

- be on oral anti-diabetic medication

- be regularly followed in one of the clinics selected for the study

- give informed consent.

\section{Sample size and selection of the participants}

The size of our sample was 213, which was calculated according to the formula: $n \geq\left(\mathrm{Z}^{2} p(1-p)\right) / d^{2}$, with $p=0.5$ as the prevalence of psychological insulin is unknown in our setting, $Z=1.96$ and $d=0.1$. As we expected a non-response rate of $10 \%$, the minimum sample size was 105.6 . In the field, we had 213 patients, representing more than twice the calculated sample size.
The participants were selected by convenience until the total of 213 patients was reached.

\section{Data collection}

The data were collected using interviews by two investigators, the principal investigator and the co-investigator. The collection tools were a data collection sheet and the 'Chinese Attitudes to Starting Insulin Questionnaire' (Ch-ASIQ). The collection sheet identified socio-demographic characteristics (age, sex, educational level, marital status, occupation, income, distance to the health centre (from home) and number of persons in charge), characteristics of diabetes (duration, current treatment, existence of complication, previous hospitalization and presence of comorbidity) and knowledge about insulin therapy (insulin type, injection site, indications, side effects, storage and administration). Insulin therapy knowledge was defined from eight questions; a good knowledge was defined in all patients with a score $\geq 5$ and poor knowledge was defined in all patients with a score between 0 and 4 . The Ch-ASIQ is the first validated psychometric questionnaire to evaluate psychological resistance to the initiation of insulin for diabetic patients in the context of primary health care. ${ }^{12}$ It includes 13 items divided into four factors: self-image and stigma, factors promoting self-efficacy, fear of pain or needles, and family support. Responses to each item were coded according to a 4-point Likert scale (total disapproval $=1$, disapproval $=2$, approval $=3$, total acceptance $=4$ ). High scores for 'time and family support' and 'self-efficiency' factors reflect a more positive attitude to insulin therapy; high scores for 'self-image and stigma' and 'fear of pain or needles' indicate negative attitudes towards insulin initiation. All factors and total score ranged from 1 to 4 with a central point of 2.5. ${ }^{12}$ Psychological insulin resistance was defined in any patient with an overall score between 0 and 2, and the acceptance of insulin therapy was defined in patients with an overall score between 3 and 4 . The Ch-ASIQ has an alpha coefficient of Cronbach's alpha for all four factors that are greater than $0.60(0.62-0.80)$. The questionnaire, translated from English into French and Lingala, was administered in one of the two local languages in which the patient was more comfortable speaking.

\section{Measures of interest for the study}

The primary variable of interest was the prevalence of PIR. The secondary variable of interest was the determinants of insulin resistance.

\section{Statistical analysis}

The data were encoded into an Excel database after cleaning and exporting to the SPSS (Statistical Package for Social Sciences software version 21, Chicago, United States). The statistical data analysis consisted of determining average, medians, interquartile range (IQR) and standard deviation for continuous variables (quantitative) and proportions of categorical variables (qualitative). The results are presented as graphs and tables. The Pearson chi-square test or the Fischer's exact test was used to compare proportions and Student's $t$-test 
and Mann-Whitney U test were, respectively, used to compare the means or medians. The determinants of knowledge and PIR were assessed through the logistic regression; the odds ratios (ORs) and their $95 \%$ confidence interval (CI) were used to estimate the strength of association between the independent and dependent variables. The value of $p<0.05$ was the statistical significance threshold.

\section{Ethical considerations}

The study obtained the approval of the Ethics Committee of the Protestant University of Congo (Register number CEU PC0031).

\section{Results}

Two hundred and thirteen patients with type 2 diabetes took part in this study, and among them were 84 men and 129 women, with a sex ratio of 1:5. The average age was $59.8 \pm 11.1$ years with extremes of 30 and 84 years. The proportion of patients who were married, had secondary school level and unemployed was, respectively, 75.1\%, $70.9 \%$ and $70 \%$. The average monthly income was $387.3 \pm 52$ USD, and the median number of people in charge of diabetic patients was four. The median duration of diabetes mellitus was 4 years in $65.7 \%$ of patients; diabetes was associated with hypertension in $65.7 \%$ of patients; $34.3 \%$ of patients had a complication of diabetes; and the most common complication was peripheral neuropathy (24.4\%). Fifty percent of patients had good knowledge of insulin therapy, and the cost of insulin therapy was estimated to be unaffordable by $75.1 \%$ of patients (Table 1 ).

The PIR was present in 91 participants (42.7\%) (Figure 1), with 33 men (15.5\%) and 58 women (27.2\%) (Table 1$)$.

Table 1 compares the general characteristics of resistant to non-resistant patients. The age up to 50 years, female gender, presence of complications of diabetes mellitus, knowledge of side effects, blurred vision, lack of knowledge about insulin therapy and the expensive cost of insulin therapy were the main variables significantly $(p<0.001)$ associated with PIR compared to non-resistant patients.

In the multivariate analysis (Table 2 ), age $\leq 50$ years (OR adjusted 2.05; 95\% CI [1.98-4.27]; $p=0.045)$, the presence of complications (OR adjusted 3.33; 95\% CI [1.68-6.60]; $p=0.001$ ), lack of knowledge on insulin therapy (OR adjusted 1.96; 95\% CI [1.08-3.71], $p=0.040$ ) and the unaffordable cost of insulin therapy (OR adjusted 2.32; 95\% CI [1.08-4.95]; $p=0.030$ ) had emerged as the main independent determinants of PIR.

\section{Discussion}

In our study, almost half of type 2 diabetic patients had PIR with independent determinants such as age $<50$ years, presence of complications, lack of knowledge about insulin therapy and low cost of insulin.
TABLE 1: Participants general characteristics and psychological insulin resistance, Kinshasa, 2017-2018.

\begin{tabular}{|c|c|c|c|c|c|c|c|}
\hline \multirow[t]{2}{*}{ Variable } & \multicolumn{2}{|c|}{$\begin{array}{c}\text { Total } \\
(N=213)\end{array}$} & \multicolumn{2}{|c|}{$\begin{array}{l}\text { Resistant } \\
(N=91)\end{array}$} & \multicolumn{2}{|c|}{$\begin{array}{c}\text { Non-resistant } \\
(N=122)\end{array}$} & \multirow[t]{2}{*}{$p$} \\
\hline & $N$ & $\%$ & $N$ & $\%$ & $N$ & $\%$ & \\
\hline \multicolumn{8}{|l|}{ Age (years) } \\
\hline$<50$ & 44 & 20.7 & 23 & 25.3 & 21 & 17.2 & 0.010 \\
\hline$\geq 50$ & 169 & 79.3 & 68 & 74.7 & 101 & 82.8 & \\
\hline \multicolumn{8}{|l|}{ Sex } \\
\hline Men & 84 & 39.4 & 33 & 36.3 & 51 & 41.8 & 0.025 \\
\hline Women & 129 & 60.6 & 58 & 63.7 & 71 & 58.2 & \\
\hline \multicolumn{8}{|l|}{ Marital status } \\
\hline Married & 160 & 75.1 & 70 & 76.9 & 90 & 73.8 & 0.358 \\
\hline Single & 53 & 24.9 & 21 & 23.1 & 32 & 26.2 & \\
\hline \multicolumn{8}{|l|}{ Educational level } \\
\hline Other & 151 & 70.9 & 61 & 67.0 & 90 & 73.8 & 0.179 \\
\hline College/university & 62 & 29.1 & 30 & 33.0 & 32 & 26.2 & \\
\hline \multicolumn{8}{|l|}{ Employment status } \\
\hline Unemployed & 149 & 70.0 & 67 & 73.6 & 82 & 67.2 & 0.195 \\
\hline Employed & 64 & 30.0 & 24 & 26.4 & 40 & 32.8 & \\
\hline \multicolumn{8}{|c|}{ Time since diabetes mellitus diagnosis (years) } \\
\hline$\leq 10$ years & 169 & 79.3 & 70 & 76.9 & 99 & 81.1 & 0.297 \\
\hline$>10$ years & 44 & 20.7 & 21 & 23.1 & 23 & 18.9 & \\
\hline Previous hospitalization & 62 & 29.1 & 23 & 25.3 & 39 & 32.0 & 0.181 \\
\hline Complications of diabetes mellitus & 73 & 34.3 & 45 & 49.5 & 28 & 23.0 & $<0.001$ \\
\hline Comorbidity & 140 & 65.7 & 58 & 63.7 & 82 & 67.2 & 0.350 \\
\hline Knowledge of side effects & 35 & 16.4 & 19 & 20.9 & 16 & 13.1 & 0.009 \\
\hline Weight gain & 30 & 14.1 & 15 & 16.5 & 15 & 12.3 & 0.250 \\
\hline Hypoglycaemia & 157 & 73.7 & 67 & 73.6 & 90 & 73.8 & 0.552 \\
\hline Blurred vision & 8 & 3.8 & 6 & 6.6 & 2 & 1.6 & 0.005 \\
\hline No knowledge of insulin therapy & 105 & 49.3 & 62 & 68.1 & 43 & 35.2 & 0.025 \\
\hline Unaffordable price & 160 & 75.1 & 78 & 85.7 & 82 & 67.2 & 0.001 \\
\hline
\end{tabular}

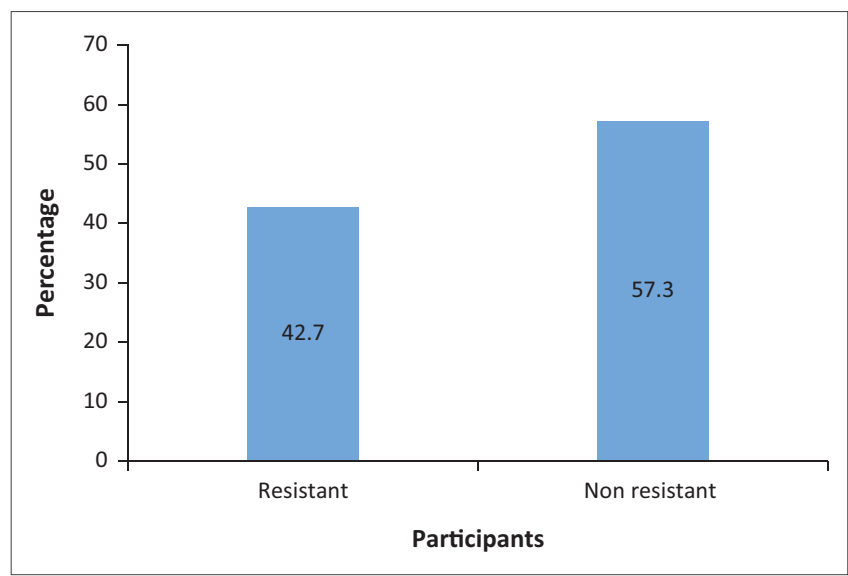

FIGURE 1: Prevalence of resistance versus acceptance of insulin among participants, Kinshasa, 2017-2018, $N=213$.

The prevalence of PIR in our study was close to the $42 \%, 40 \%$ and $47.2 \%$ reported in the studies conducted, respectively, in Bangladesh, ${ }^{13}$ the United States ${ }^{14}$ and Egypt. ${ }^{15}$ This prevalence is lower than $51 \%, 53.29 \%, 70.6 \%$ and $72 \%$ found in Asia. ${ }^{16,17,18,19}$ On the other hand, it is higher than $27 \%, 28 \%$ and $33 \%$ reported by European authors. ${ }^{3,20,21}$ This high prevalence in our study may be because of a weak integration of diabetes care at the primary care level, misinformation and lack of training of diabetic patients on diabetes, its complications and the benefits of insulin therapy. Differences in the age of patients included in the various studies may also explain this disparity in PIR frequency. ${ }^{22}$ Low knowledge of diabetes can 
TABLE 2: Determinants of resistance to insulin therapy in multivariate analysis.

\begin{tabular}{|c|c|c|c|c|c|c|}
\hline \multirow[t]{2}{*}{ Variable } & \multicolumn{3}{|c|}{ Univariate } & \multicolumn{3}{|c|}{ Multivariate } \\
\hline & $p$ & OR & $\mathrm{Cl} 95 \%$ & $p$ & $\begin{array}{c}\text { OR } \\
\text { adjusted }\end{array}$ & $\mathrm{Cl} 95 \%$ \\
\hline \multicolumn{7}{|l|}{ Age (year) } \\
\hline$\geq 50$ & - & 1.00 & - & - & 1.00 & - \\
\hline$<50$ & 0.015 & 1.63 & $1.38-3.17$ & 0.045 & 2.05 & $1.98-4.27$ \\
\hline \multicolumn{7}{|l|}{ Sex } \\
\hline Male & - & 1.00 & - & - & 1.00 & - \\
\hline Female & 0.041 & 1.62 & $1.72-2.21$ & 0.184 & 1.53 & $0.82-2.89$ \\
\hline \multicolumn{7}{|c|}{ DM complication } \\
\hline No & - & 1.00 & - & - & 1.00 & - \\
\hline Yes & $<0.001$ & 3.28 & $1.82-5.92$ & 0.001 & 3.33 & $1.68-6.60$ \\
\hline \multicolumn{7}{|c|}{ Knowledge of side effects } \\
\hline No & - & 1.00 & - & - & 1.00 & - \\
\hline Yes & 0.013 & 1.75 & $1.84-3.63$ & 0.683 & 1.22 & $0.48-3.12$ \\
\hline \multicolumn{7}{|l|}{ Blurred vision } \\
\hline No & - & 1.00 & - & - & 1.00 & - \\
\hline Yes & 0.018 & 4.24 & $1.18-9.49$ & 0.319 & 2.74 & $0.38-9.77$ \\
\hline \multicolumn{7}{|c|}{ Knowledge of insulin therapy } \\
\hline Yes & - & 1.00 & - & - & 1.00 & - \\
\hline No & 0.004 & 2.25 & $1.72-3.46$ & 0.04 & 1.96 & $1.03-3.71$ \\
\hline \multicolumn{7}{|l|}{ TTT cost } \\
\hline Affordable & - & 1.00 & - & - & 1.00 & - \\
\hline Unaffordable & 0.003 & 2.93 & $1.46-5.88$ & 0.03 & 2.32 & $1.08-4.95$ \\
\hline
\end{tabular}

$\mathrm{DM}$, diabetes mellitus; TTT, treatment; $\mathrm{OR}$, odds ratio; $\mathrm{Cl}$, confidence interval.

negatively affect beliefs and perceptions about insulin therapy as demonstrated by other authors who have evaluated PIR. ${ }^{22}$ Being under 50 years of age has been one of the determinants of PIR in our study. Age as a determinant has not been found by other authors. ${ }^{14}$ The diverse population studied, the method used and the sample size can explain this difference. Machinani et al. conducted their study on different ethnic groups (African Americans and Latin Americans), ${ }^{14}$ whereas our study focused on a homogenous population in terms of race with participants living in the same socioeconomic and cultural context. Restrictions and the adaptation of lifestyle habits are all factors that may explain the prevalence of PIR in patients under 50 years of age.

Nearly half of the patients had diabetes complications that were associated with a negative attitude towards insulin therapy. This observation is similar to that made by Lee in China and Brod et al., in a systematic review..$^{22,23}$ Complications, especially in a patient undergoing treatment, are experienced as an injustice and a progression that can lead to death. Lack of knowledge about insulin therapy emerged as one of the main factors associated with PIR in our study. This observation has already been made by Karter et al, who linked the lack of knowledge about diabetes to a quality problem of communication between caregiver and patient. ${ }^{24}$ The reasons given by the patients included, among other things, not having received information, misunderstanding the information received either because of a vision problem, or the inability to read the documents made available to them. ${ }^{24}$ Other studies have found that fear of initiation to insulin therapy was associated with poor beliefs: fear of injections, stigma, addiction, symptoms synonymous with complications and death, the onset of hypoglycaemia and complications. ${ }^{8,25}$ In the study, it was also noted that patients did not have a knowledge of insulin indications and adverse effects at injection sites. Poor perception of insulin therapy as the basis of PIR in our midst is also linked, among other things, to the low level of education of patients as also found by Jasper et al..$^{25}$ The cost of insulin was considered unaffordable in three quarters of cases and in almost 9 out of 10 patients, respectively, in the whole group and in patients with a negative attitude towards insulin therapy. The unaffordable cost was found to be a significant barrier to insulin therapy and a factor favouring PIR in Nigeria with an average monthly cost of $\$ 39.00 .{ }^{26,27,28}$ The lack of state subsidies, the grouping of patients in association with diabetes and a policy of diabetes control in the face of the progress of the pharmaceutical industry are all factors in favour of the PIR. The absence of a social policy affects the entire supply and distribution circuit and increases the unit price of insulin. Government involvement in the purchase of insulin, and the choice of providers and products can improve insulin availability. ${ }^{29}$

\section{Conclusion}

This study showed that almost half of the patients with type 2 diabetes had PIR with the main determinant factors related to the patient and the health system. The establishment of a therapeutic education programme on diabetes, improved 'provider-patient' communication and the development of approaches to geographic and financial access to essential drugs are crucial to reduce the prevalence of PIR and its deleterious consequences on the control of diabetes mellitus and the quality of life of patients.

\section{Acknowledgements Competing interests}

The authors declare that they have no financial or personal relationships that may have inappropriately influenced them in writing this article.

\section{Authors' contributions}

S.L.R. is the author of the submitted and defended dissertation at the Department of Family Medicine, Protestant University, Congo, from which this article is drawn. F.J.-P.L. supervised the dissertation and produced the first version of the article. He contributed to the correction of the translation from French to English. L.F.B. co-supervised the dissertation and contributed as internal reviewer of the article. O.A.G. contributed to the review of the article and made contribution to the interpretation of statistical data. L.P.N. coordinated the entire article writing process, provided feedback on the results and discussion and produced the abstract.

\section{Funding information}

This research received no specific grant from any funding agency in the public, commercial or not-for-profit sectors.

\section{Data availability statement}

Data sharing is not applicable to this article as no new data were created or analysed in this study. 


\section{Disclaimer}

The views and opinions expressed in this article are those of the authors and do not necessarily reflect the official policy or position of any affiliated agency of the authors.

\section{References}

1. Hall V, Thomsen RW, Henriksen O, et al. Diabetes in sub-Saharan Africa 1999-2011: Epidemiology and public health implications. A systematic review. BMC Public Health. 2011;11:564. https://doi.org/101186/1471-2458-11-564

2. Peyrot $M$, Rubin $R$, Lauritzen $T$, et al. Resistance to insulin therapy among patients and providers: Results of the cross-national diabetes attitudes, wishes and needs (DAWN) study. Diabetes Care. 2005;28:2673-2679. https://doi.org/10.2337/ diacare.28.11.2673

3. UK Prospective Diabetes Study (UKPDS) Group. Intensive blood-glucose control with sulphonylureas or insulin compared with conventional treatment and risk of complications in patients with type 2 diabetes (UKPDS 33). UK Prospective Diabetes Study (UKPDS) Group. Lancet. 1998 352(9131):837-853. https://doi. Diabetes Study (UKPDS) Group. Lanc
org/10.1016/S0140-6736(98)07019-6

4. Taylor Jr CG, Taylor G, Atherley A, et al. The Barbados Insulin Matters (BIM) study: Barriers to insulin therapy among a population-based sample of people with type 2 diabetes in the Caribbean island of Barbados. J Clin Transl Endocrinol. 2 diabetes in the Caribbean island of Barbados. J C

5. $\mathrm{Ng} \mathrm{C}$, Lai $P$, Lee $Y$, et al. Barriers and facilitators to starting insulin in patients with type 2 diabetes: A systematic review. Int J Clin Pract. 2015;69 (10):1050-1070. https://doi.org/10.1111/ijcp.12691

6. Haque $M$, Navsa $M$, Hayden ES, et al. Barriers to initiating insulin therapy in patients with type 2 diabetes mellitus in public-sector primary health care centres in Cape Town. S Afr Med J. 2005;95:798-802. https://doi.org/10.1080/22201009. 2005.10872127

7. IDF diabetes atlas -8 th edition [homepage on the Internet]. [cited 2018 Nov 11] Available from: http://www.diabetesatlas.org/

8. Bieleli El, Moswa JL, Ditu M, et al. Prévalence du diabète sucré au sein de la population de Kinshasa. Congo Méd. 2000;2(15):1058-1061

9. Kasiam JB, Longo-Mbenza B, Nge Okwe A, et al. Prevalence, epidemic's stage and risk factors of diabetes mellitus in Kinshasa Hinterland. Int J Diabetes Metab. 2008;16:50-59.

10. Katchunga P, Hermans MP, Manwa B, Lepira F, Kashongwe Z, M'Buyamba-Kabangu $J R$. Hypertension artérielle, insulinorésistance et maladie rénale chronique dans un groupe de diabétiques de type 2 du Sud-Kivu, RD Congo. Néphrol Thér. un groupe de diabétiques de type 2 du Sud-Kivu, RD Congo. Nêp
2010;6(6):520-525. https://doi.org/10.1016/j.nephro.2010.04.002

11. Makulo J, Rissassi, Nseka M, et al. Albuminurie pathologique lors du dépistage du diabète en milieu semi-rural (cité de Kisantu en RD Congo). Néphrol Thér. 2010;6(6):513-519. https://doi.org/10.1016/j.nephro.2010.04.006

12. Sau-Nga F, Wong CKH, Chin WY, et al. Association of more negative attitude towards commencing insulin with lower glycosylated hemoglobin (HbA1c) level: survey on insulin-naive type 2 diabetes mellitus Chinese patient. J Diabetes Metab Disord.2016;15:3. https://doi.org/10.1186/s40200-016-0223-0

13. Khan H, Lasker SS, Chowdhury TA. Prevalence and reasons for insulin refusal in Bangladeshi patients with poorly controlled type 2 diabetes in East London. Diabetic Med. 2008;25:1108-1111. https://doi.org/10.1111/j.1464-5491.2008.02538.x
14. Machinani S, Bazargan-Hejazi S, Hsia SH. Psychological insulin resistance among low-income, US racial minority patients with type 2 diabetes. Prim Care Diabetes. 2013;7:51-55. https://doi.org/10.1016/j.pcd.2012.11.003

15. El Shafei MM, Sayyah HS, Hussein R. Psychological insulin resistance in patients with type 2 diabetes mellitus. Egypt J Psychiatr. 2015;36:60-65. https://doi. org/10.4103/1110-1105.153794

16. Shah SMA, Butt Z, Hussain K. Factors leading to psychological insulin resistance among patients with type 2 diabetes mellitus. Ann Pak Inst Med Sci. 2017;13(3):226-230.

17. Nur Azmiah Z, Zulkarnain AK, Tahir A. Psychological insulin resistance (PIR) among type 2 diabetes patients at public health clinics in federal territory of Malaysia. Int Med J Malaysia. 2011;10(2):7-12.

18. Wong S, Lee J, Ko Y, et al. Perceptions of insulin therapy amongst Asian patients with diabetes in Singapore. Diabet Med. 2011:28:206-211. https://doi. org/10.1111/j.1464-5491.2010.03195.x

19. Yiu MP, Cheung KL, Chan KW. A questionnaire study to analyze the reasons of insulin refusal of DM patients on maximum dose of oral hypoglycemic agents (OHA) among3 GOPC in Kowloon West Cluster [homepage on the Internet]. [cited
2018 Nov 11]. Available from: http://www.ha.org.hk/haconvention/hac2010/ proceedings/pdf/Poster/spp-p5-38.pdf

20. Polonsky WH, Fisher L, Guzman S, et al. Psychological insulin resistance in patients with type 2 diabetes: The scope of the problem. Diabetes Care. 2005;28:25432545. https://doi.org/10.2337/diacare.28.10.2543

21. Larkin ME, Capasso VA, Chen $\mathrm{CL}$, et al. Measuring psychological insulin resistance: Barriers to insulin use. Diabetes Educ. 2008;34(3):511-517. https://doi. org/10.1177/0145721708317869

22. Brod M, Lessard AS, Meneghini L. Psychological insulin resistance: Patient beliefs and implications for diabetes management. Qual Life Res. 2009;18;23-32. https:// doi.org/10.1007/s11136-008-9419-1

23. Lee KL. Psycholosocial factors associated with psychological insulin resistance in primary care patients in Hong Kong. J Clin Transl Endocrinol. 2015;2(4):157-162. https://doi.org/10.1016/j.jcte.2015.10.001

24. Karter AJ, Subramanian U, Saha $C$, et al. Barriers to insulin initiation: The translating research into action for diabetes insulin starts project. Diabetes Care. 2010;33(4):733-735. https://doi.org/10.2337/dc09-1184

25. Jasper US, Opara MC, Pyiki ED, et al. Knowledge of insulin use and its determinants among Nigerian insulin requiring diabetes patients. J Diabetes Metab Disord. 2014;13:10. https://doi.org/10.1186/2251-6581-13-10

26. Fadare J, Olamoyegun M, Gbadegesin BA. Medication adherence and direct treatment cost among diabetes patients attending a tertiary healthcare facility in Ogbomosho, Nigeria. Malawi Med J. 2015;2(2):65-70. https://doi.org/10.4314/ mmj.v27i2.7

27. Management Sciences for health. International medical products price guide [homepage on the Interne]. c 2015 [cited 2018 Nov 11]. Available from: https:// www.msh.org/resources/international-medical-products-price-guide.

28. Gulam AH, Otieno CFF, Omondi-Oyoo G. Prevalence of psychological insulin resistance among patients with type 2 diabetes at Kenyata National Hospital, Kenya. Health Sci J. 2017; 11:3. https://doi.org/10.21767/1791-809X. 1000508

29. Novo Nordisk. Sustainability report 2003 [homepage on the Internet]. [cited 2018 Nov 11]. Available from: https://www.unglobalcompact.org/system/attachments/7580/ original/NovoNordisk_Sustainability_Report_2003.pdf?1282019220 